presents a certain amount of organized information in regard to a portion of the science of botany, and also that it gives us the result of ten years of experience in working out the method of undergraduate instruction in botany in one of the foremost botanical laboratories in the country. The authors here endeavor to present "the fundamental facts and principles of the science," and they hold that these should precede the work of most other subdivisions of botanical investigation. Thus they point out that " a study of the very important subject of plant pathology must presuppose the fundamentals of morphology and physiology; paleobotany is, in part, the application of morphology and ecology to fossil plants; and scientific plant breeding rests upon the foundations laid by morphology, physiology and ecology."

Here we have then an expression of the opinion of three eminent teachers as to what should be the "content" of botanical instruction, and its proper sequence, and it is that the structure of plants must be presented first in an orderly sequence from the lower to the higher forms, and that then the activities of plants must be considered, while the relations of plants to one another and to their physical environment may well come after form and function have been pretty fully considered. Then when these fundamental subjects have been pretty well mastered the student is ready to go forward into pathology, paleobotany, plant breeding, etc. The book is thus a contribution to botanical pedagogy. This aspect of the book is, we believe, most important at this time when some teachers have the notion that it makes little difference in what order the subdivisions of botany are taken up.

The morphological part plunges at once into a study of the Thallophytes, taking in succession (1) Myxomycetes, (2) Schizophytes, (3) Algæ, (4) Fungi, followed by Bryophytes, Pteridophytes and Spermatophytes, and a suggestive chapter entitled "Organic Evolution." The treatment is admirable, and the more than six hundred illustrations make this one of the most satisfactory morphological texts with which we are acquainted. The student who runs up through the vegetable kingdom in the sequence here given can not fail to secure a clear conception of its general plan, as well as of its probable mode of evolution.

The second part, devoted to Physiology, takes up the subject under five heads, viz., (I.) the material income of plants, (II.) the material outgo of plants, (III.) nutrition, (IV.) destructive metabolism, (V.) growth and movement. The treatment here is as satisfactory as in Part I., and as we read the lucid sentences we are reminded forcibly of the great loss suffered by botanical science through the death of Professor Barnes. We can not refrain from quoting a few sentences, both for the substance and as illustrating the forcible presentation.

Transpiration, far from being a function of plants, is an unavoidable danger. That it is a danger, a real menace to life, is almost a matter of common observation. Millions of plants perish annually because the outgo of water is greater than the income. A loose soil and an exposed situation, sudden extreme evaporation due to a hot dry wind and a blazing sun, or prolonged drought, are causes of death too well known to farmers in some regions. Scarcely a plant escapes the loss of some parts by reason of shortage in the water supply; and in temperate regions, with the average rainfall (say $100 \mathrm{~cm}$. annually), few plants attain the development of which they are capable with a larger water supply. The luxuriant weed of well-watered ground compared with the same weed, meager and dwarfed on the dry wayside, illustrates what a menace to life and vigor is the evaporation from plants.

It is greatly to be deplored that the facile hand that penned, and the active and original mind that framed such vigorous and lucid sentences are forever stilled, and that the work here so well begun must stop, or be carried forward by others. And who is there who can take the place of Barnes?

The University of Nebraska

Charles E. Bessey

Attention and Interest: A Study in Psychology and Education. By Felix Arnold, Ph.D. New York, The Macmillan Company. 
In this volume Dr. Arnold presents the results of a study of the practical aspect of his problem. "The present essay on the psychology of Attention and Interest," says the writer, "is an attempt to classify and arrange the many facts that have been brought to light by numerous experiments in the psychological laboratories." In order to allow of the fullest review of such facts the conception of attention has been made as simple as possible; as developed in the Introduction, attention is the correlative of the development of an "object" in consciousness. The appearance of such an object of consciousness is not incidental to mental activity; in all developed consciousness it is its characteristic form. The problem of the essay is an inquiry into the history and values of this characteristic activity of mind. Attention and interest are therefore considered in their intrinsic relations as systems of ideal elements, in their conditions as phases of a teleological existence, and in their relation to concomitant or consequent physical changes.

The writer's interest is thus not in giving a logical formulation to the conception of these phases of mental activity, nor in seeking the inner distinctions upon which their separation as ideal forms is based. He therefore systematically subordinates the guiding conceptions which may have lain back of an individual investigation and ignores the theoretical formulation to which it may have led, in order to utilize all established facts in the given field. "I have felt myself bound," Dr. Arnold says, "not to uphold any special theory or school, but to present the facts as they seem to be." With reference to all purely psychological problems the book may therefore be called selective; it represents a sifting of the literature with a view to presenting in a succinct review the ascertained facts concerning attention and interest, in their manifold connections, which are of importance to the teacher. As the writer's motive is not critical but practical, and as the aim is to make the reader acquainted with those special aspects of the subject which are of value in connection with the problems of the school- room, the discussion falls into two parts, first, the presentation of the results of experimentation, and second, the application of these results to school-room practise. The résumé of literature is given separately for each of the two topics, but the applications are considered in a single discussion. The book thus falls into three parts: (I.) Attention, (II.) Interest, (III.) Education. In dealing with each topic the writer simplifies the discussion by separating his description of the facts from their explanatory, developmental and illustrative treatments, which are considered in separate sections.

By its aim the book disarms criticism for any lack of rigid psychological criteria in the matters of definition and limitation of discussion, since it is a summary of results determined primarily by the needs of the teacher. Though the psychologist may rightly demand a definition of attention, or of interest, in such terms as to limit the view to phenomena of consciousness alone, the teacher must take into account the whole psychophysical situation in which the child is placed if he aspires to stimulate his attention or direct his interest. He must study the effects of extraneous stimulation, fatigue, nutritive condition and motor control, as well as those of practise, rest, age, mental development and the like. The mind's activities are both physically and historically conditioned, and their supplementation or ideal control is made possible by this correlation alone. From the teacher's standpoint it is just these extrinsic features of attention and interest-with which Dr. Arnold's book so largely deals-which are of real importance. The analysis of inner distinctions and correlations in the ideal systems themselves which may be called their intrinsic features are, as Herbart long ago pointed out, least of all to be considered in such a connection, though they may constitute the primary phenomenon for the introspective psychologist. Dr. Arnold's summary of these objective stimuli to interest, and of the physical conditions and manifestations of attention is full and well presented. In the opinion of the reviewer it is here that the 
value of the book lies. The varied information which it brings together in a compendious form will be found useful by the psychological student and lecturer as well as by the teacher.

When the writer undertakes to bring his materials together in a systematic review the result is less satisfactory. It is, of course, impossible to keep clear of theory in any systematic presentation of fact; and while the necessity for such underlying conceptions may be masked so long as one is concerned only with reporting the results of individual experiments, the lack of guiding principles will appear whenever the attempt is made to bring together a group of particulars in a systematic review. Dr. Arnold's recapitulation of the discussion of attention, for example, suffers from the lack of a principle of division distinctly conceived and persistently adhered to. He begins this review by pointing out that "attention must be considered from two points of view," the sensory and the motor, a dualism which is expressed also in the terms "ideal" and physiological. The reader naturally assumes that this statement, with which the recapitulation begins, represents the last result of the writer's analysis, that the distinction is fundamental to the phenomena of attention. But Dr. Arnold goes on immediately to say that there are two aspects of attention, the subjective and the objective, of which the former includes both the sensory and the motor processes above mentioned. If this be so, it should be pointed out on behalf of the reader that the conditions of a good exposition surely require the more fundamental distinction to be presented first. That the latter distinction is basal appears from the following page, in which the subjective-objective is made the most general phase of the discussion.

The schema in question formulates the phenomena of attention in a way which is of permanent value, but as the grouping is not, in strictness, the order followed in the previous discussion, it can scarcely be called a recapitulation. One must drop the old subdivisions which he carried in mind throughout the reading, and substitute a new-though of course congruous-conception of relations. A question, too, may be raised concerning the propriety of the terms here employed. The aptness of the term "objective" to a summarization of the characteristics of clearness, distinctness and persistence may be granted, since these are, properly speaking, attributes of the object before consciousness; but a certain violence is done to a term already too loosely employed when accommodation and fixation, respiration and vaso-constriction, as well as fusion and free association, are made to fall within the field of the "subjective." Still more do the details of the schema reveal the need of logical formulation as well as of full citation of individual fact. The "subjective" aspect of attention, for example, is considered under the two heads, motor and sensory; but under the former appears also a subdivision entitled "motor," comprising the phenomena of innervation, diffusion and control. It is confusing, too, that under this term-which is not only popularly opposed to "sensory," but is also made its logical alternative in the present scheme-there should be made to fall the two subdivisions "sensory" and "motor" as minor terms. There is therefore the further contradiction that the term "sensory," which constitutes the basis of the second general division, should appear also as a special constituent of the first group of phenomena.

In each phase of the discussion Dr. Arnold has added to his description of the phenomena a consideration of their development in the individual mind. This is an important addition to the study which might profitably receive even more space than has been given to it. A series of illustrations is systematically appended to each chapter of the book. While these are in general well chosen, the reviewer finds some of them puzzling; but effective illustration is, after all, not only a matter of happy invention in the writer, but also one of idiosyncratic temperament in the reader, and the instances cited may nowhere present such obscurity to another mind.

\section{Robert MacDougall}

